\title{
The effect of petroleum rationing on road traffic fatalities in the South of Iran during 2004-2009
}

\author{
Moradinazar M, MSc ${ }^{* 1}$, Najafi F, $\mathrm{PhD}^{2}$, Hasanzadeh $\mathrm{J} \mathrm{PhD}^{3}$ \\ 1- PhD Student, Research Center for Environmental, Dept. of Health, Kermanshah University of Medical Sciences, Kermanshah, \\ Iran. 2- Associate Prof., Research Center for Environmental, Dept. of Health, Kermanshah University of Medical Sciences, \\ Kermanshah, Iran. 3- Associate Prof., Dept. of Epidemiology, Shiraz University of Medical Sciences, Shiraz, Iran.
}

\begin{abstract}
Received: January 2014, Accepted: January 2015

Background: This study attempted to investigate traffic accident fatalities during 2004-2009 and the effect of fuel rationing on traffic accident fatalities.

Materials and Methods: This was a cross-sectional study on available data of all traffic accident fatalities in Fars Province, Iran, during 2004-2009. To identify and fit the best model, various instruments, including the autocorrelation function (ACF), partial autocorrelation function (PACF), and Akaike information criterion (AIC), were used. To determine the accuracy of the model, the residual chart was evaluated in terms of independency, normality, and stationary. Then, the best model in terms of more accurate estimation was selected and analyzed using ITMS, Minitab, and Microsoft Excel software.

Results: During 2004 to 2009, 12954 people died due to road traffic fatalities in Fars Province. Among them, $10442(80 \%)$ were male, and mean age at death was $36 \pm 20$. The number of traffic accident fatalities in Fars Province reduced from 45.5 per 100000 in 2004 to 44.8 per 100000 in 2007. After petroleum rationing, the traffic accident fatality average further reduced (to 42.2 per 100000 in 2009). There was a difference between the observed value and predicted value with two different predication methods, as the number of observed fatalities was less than the estimated numbers. Seasonal Holt-Winters and autoregressive moving average (ARMA) methods' predications were a close estimation of the accident fatality rate after petroleum rationing, and the difference between their estimations was not considerable.

Conclusions: Although the overall rate of fatalities reduced after petroleum rationing, variation in fatality rate did not show any association with petroleum rationing. However, decrease in fatalities had a seasonal pattern. Further decrease in road traffic fatalities requires reinforcement of educational programs as well as application of effective laws.
\end{abstract}

Keywords: Traffic Accident, Petroleum, Rationing, Time Series, Seasonal.

\section{Introduction}

Traffic accidents are a major health issue in developing countries. Such accidents, under any conditions, can lead to physical, mental, and social damages which impose a huge burden on the health system and families in the long term (1-3). According to the World Health Organization (WHO) report, 1.2 million people are killed in road crashes each yearand as many as 50 million people are injured, worldwide (4). If preventive measures are not taken in this regard, the number of deaths and injuries will increase by $65 \%$ all over the world $(4,5)$. In Iran, with a population of about71 million people, there are about 17 million cars (i.e. 1 car for every 4 people), thus, Iran has the highest number of cars among Eastern Mediterranean countries (6-8). Not proportional to such high

\footnotetext{
* Corresponding author: Mahdi Moradinazar, Research Center for Environmental, Dept. of Health, Kermanshah University of Medical Sciences, Kermanshah, Iran. Email: moradi.mehdi1363@.yahoo.com
} 
number of cars in Iran, road traffic accident rate, death rate, and disability-adjusted life year (DALY) lost because of road traffic accidents in Iran are higher than average global and regional values $(4,9,10)$. This has caused the recognition of road traffic accident as a main health problem not only in Iran, but also worldwide $(11,12)$.

Iran is a developing country with continuous improvements in transport infrastructure, quality of vehicles, driver training, traffic laws, and emergency road health care. These are also the main factors which contribute to road traffic injuries. In addition to all these factors, the police have recently enhanced the controls on all roads specifically during public holidays. One of the other factors affecting the number of car journeys within each country, which in turn affect the number of road traffic injuries, is the price and availability of fuel for cars. The price of gasoline and other petroleum products in Iran, because of subsidies, were much lower than the world price. However, in 2007, the government tried to remove fuel subsides and rationings in order to control the increasing gasoline consumption trend. In this study, we aimed to investigate the effect of gas rationing on the number of fatalities due to road traffic injuries by investigating trends in road traffic fatalities (13).

\section{Materials and Methods}

This study was a cross-sectional study on fatalities due to road traffic accidents in Fars Province from 2004 to 2009. Fars Province is located in the South of Iran with a population of more than 4.5 million people. In the province, $61 \%$ of the population lives in urban areas. The main road network is about $2229 \mathrm{~km}, 569 \mathrm{~km}$ of which comprise of highways (14). Road traffic fatalities were separated from death registry data collected by health centers of each province in which all the appropriate resources were used including data from hospitals, cemeteries, the Legal Medical Organization, and rural health centers. The data contains variables such as age, gender, time of incident and death, and place of accident. Health center personnel record the data on a daily basis, but data from all over the province are collected on a monthly basis. Information related to cause of death were recorded by a coroner in each city in which the disease coding system was based on the 3 digit coding of the International Classification Of Diseases $10^{\text {th }}$ revision (ICD-10) and external mortality and injury causes were classified using V01 to V99 codes (15). For the purpose of this study, all road traffic fatalities involving a motor vehicle with at least two wheels were included if the victims were inhabitants of the Fars Province. The amount of fuel consumption was extracted from the Fars Energy Consumption Optimization Organization, and the population of the province was obtained from the Civil Registration Organization of Fars Province.

After the data collection, the road traffic fatality data was entered into Microsoft Excel software (Microsoft Corporation, Redmond, WA, USA), and repetitions were eliminated by matching name, family name, father's name, and national identity. Moreover, outlier of traffic accident fatalities was excluded or reduced by statistical methods (16). To show more accurate trend of traffic accident fatalities, we made the data stationary (trend removal, data seasonal component, and variance constant). Then, we used Box-Jenkins models for modeling trends in fatalities. In this study, to identify and fit the best model, various instruments, including autocorrelation function (ACF), partial autocorrelation function (PACF), and Akaike information criterion (AIC), were applied. To determine the accuracy of the model, the residual chart was evaluated in terms of normality and stationary. Then, the best model in terms of better estimation and lower error (sum squared error and mean squared error) was selected. For data analysis, ITSM version 7 (the ITSM package is used to analyze and display the 
properties of time series data), Minitab (version 16; Minitab Inc., State College, PA, USA), and Microsoft Excel software were used (17). In addition to the data description, t-test was used to compare group's means in men and chi-square test was used for comparison of averages. Women and Poisson regression were further applied to determine changes in frequency of fatalities over time. All $\mathrm{P}$ values of greater than 0.05 were considered significant.

\section{Results}

During 2004 to 2009, 12954 people died due to road traffic accidents in the Fars Province, of which 10442 (80\%) were male and 2512 (20\%) were female. The mean age at death from road accidents was $36 \pm 20$, the corresponding value for women and men were $38 \pm 23$ and $35 \pm 19$, respectively $(\mathrm{P}<0.001)$. Death attributed to road traffic accidents accounted for $12 \%$ of total deaths of the province. Road traffic fatalities are different among men and women, as this ratio was $14 \%$ among men and $5.5 \%$ among women $(\mathrm{P}<0.001)$.

In total, Fars Province, in 2008, consumed about $6.51 \%$ of the total $1,595,745,000 \mathrm{~L}$ petroleum in Iran, and was in the fourth rank in terms of petroleum consumption after Tehran, Khorasan, and Isfahan. After petroleum rationing and increasing of petroleum substances price in June 2007, gas consumption decreased in the province from 12 to 9 million L per month, and this reduction was significant (Figure 1) $(\mathrm{P}<$ 0.001).

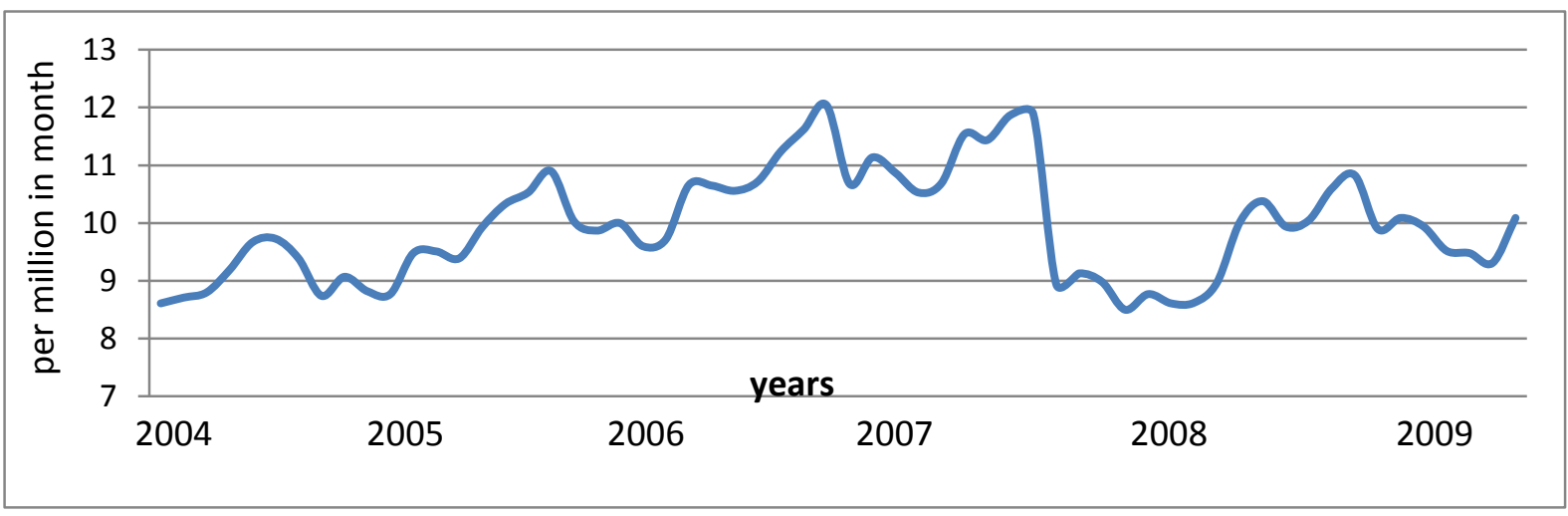

Figure 1. Petroleum consumption trend in Fars Province during 2004-2009

The average of road traffic fatalities in Fars Province was 45 per 100000,18 per 100000 for females and 73 per 100000 for males, which is statistically significant $(\mathrm{P}<0.001)$. As shown in figure 2, the number of traffic accident fatalities in Fars Province reduced from 45.5 per 100000 in 2004 to 44.8 per 100000 in 2007 ( $\mathrm{Y}=-0.11$ month +48$)(\mathrm{P}=0.032)$. After petroleum rationing, the average of traffic accident fatalities has further reduced (to 42.2 per 100000 in 2009) (Y=-0.23 month +47$)$. Therefore, the prediction by seasonal Holt-Winters and autoregressive moving average (ARMA) methods was higher than that observed. The value predicted by the two methods was a close estimation of the traffic accident fatality rate after petroleum rationing and the difference in their estimations was small. However, there was a difference between the observed value and predicted value with two different predication methods, as the number of observed fatalities was less than the estimated numbers. 


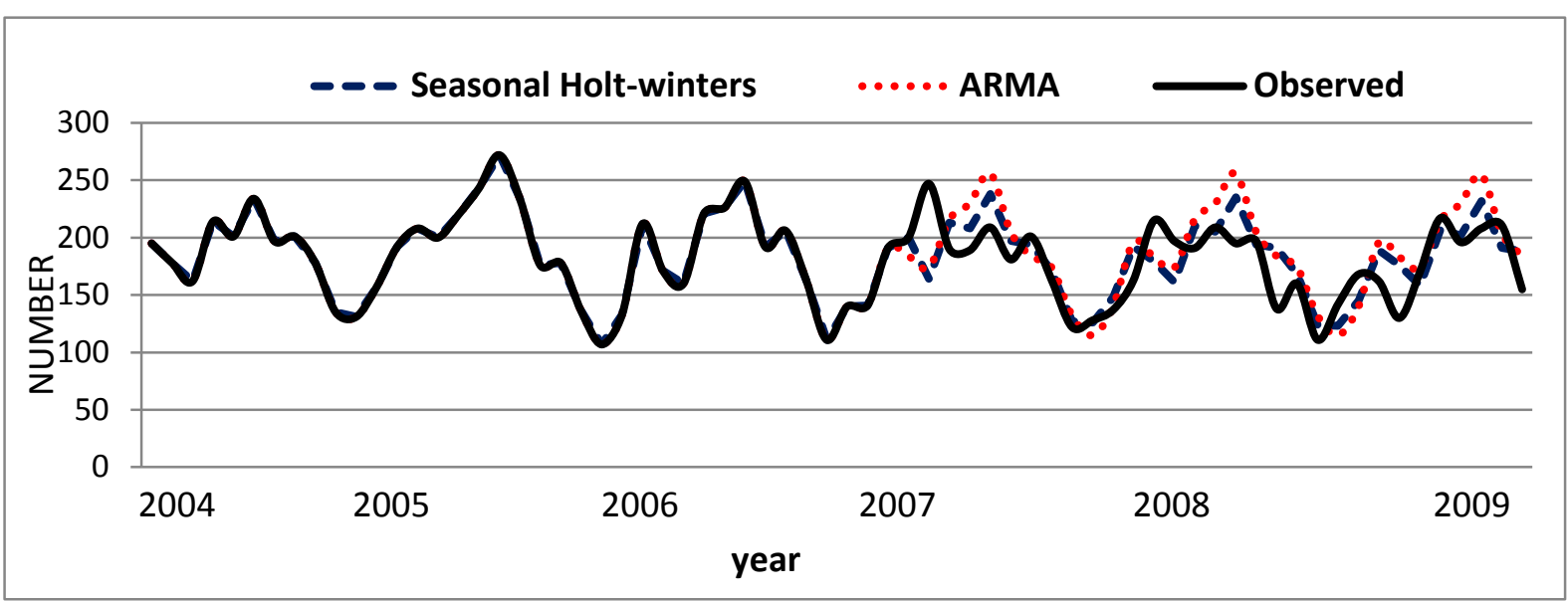

Figure 2. The number of observed and expected cases after petroleum rationing

The trend of fatalities based on gender showed a descending trend among men $(\mathrm{Y}=-0.24$ month $+82)(\mathrm{P}=0.02)$, and an ascending trend among women $(\mathrm{Y}=0.9$ month +15$)(\mathrm{P}=0.004)$.
Interestingly, the highest decrease and increase in fatalities among men and women, respectively, have occurred after petroleum rationing (Figure 3).

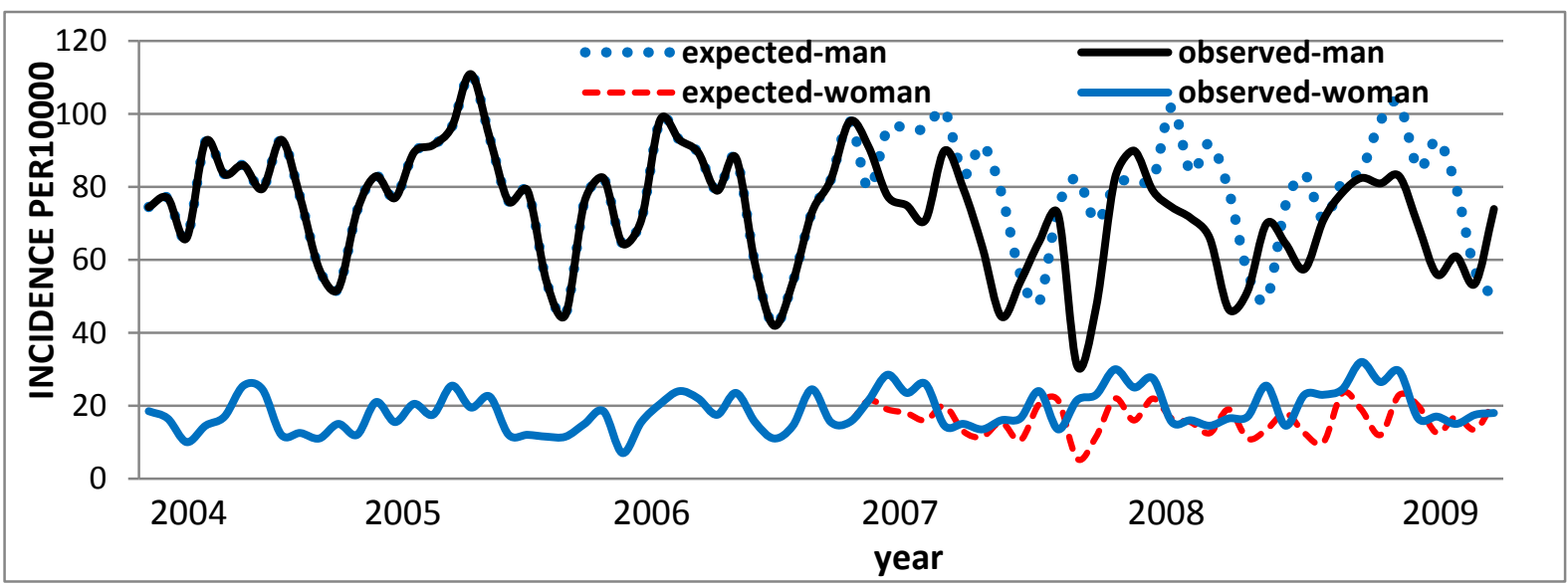

Figure 3. The effect of petroleum rationing on the number of death cases of traffic accidents based on gender

According to our results, the monthly and seasonal models can, respectively, describe $35 \%$ and $41 \%$ of the fatalities among men. However, traffic accident fatalities among women did not show any regular trend.In the present study, there was no statistically significant association between petroleum consumption and road traffic fatalities $(r=0.175, P=0.18)$. In fact, traffic accident fatality has a seasonal trend with its highest and lowest rates in September and January, respectively.

\section{Discussion}

The current study results showed that fuel consumption in Iran had an ascending trend before the increase of petroleum price and rationing. In fact, decrease in fatality rate due to traffic accidents showed a quadratic function 
affected mostly by season. Thus, although the results of the current study showed a reduction in road traffic fatalities after petroleum rationing, we cannot find an exact association between fuel consumption and such fatalities. According to our findings, the fatalities model is affected by seasonal pattern more than fuel consumption and petroleum rationing, as such fatalities occurred in summer more than other seasons. Similar studies conducted in other parts of the world have also shown that traffic accident fatalities have a seasonal pattern (1517).

The present study indicated that the traffic accident fatalities model is changing in our society, as it showed an increase in traffic accident fatalities among women and reduction among men in Fars Province. Such changes have been observed specifically after petroleum rationing.

Various factors may have contributed to such an increase in fatalities among women. In Iran, the improvements in the socio-economic status of families and women have resulted in an increase in their participation in activities outside of the home, and in turn, their use of vehicles. This finding is similar to that from other parts of Iran (18) and other countries $(19,20)$. In the present study, although fatality rate decreased over the period of the study, it was 4 times higher among men than women. This finding was consistent with that of similar studies in Iran (18), United States (21), France (22), Sweden, Spain (23), India, Thailand (24), and many other countries $(4,25)$.

The average of traffic accident fatalities in the Fars Province was higher than the average value in Iran (about 30 per 100000). One of the important reasons for this higher rate of fatality in Fars Province can be the higher ratio of cars to population in the province compared to that of the whole of Iran (5). Keeping in mind that mortality rate due to road traffic accidents in Iran is higher than the world, which is estimated to be 19 to 22 per 100000 , illustrates the severity of the situation in Fars Province $(4,7)$. There are several factors that contribute to these findings. The existence of inexperienced and careless drivers in Fars Province as well as Iran are two important factors (26). In addition, the use of old cars plus the existence of few standard roads are other contributing factors (6). While drinking does not seem to be a big problem in Muslim countries, such as Iran, seat belt and helmet use and possible lower quality of prehospital and hospital cares, compared to developed countries, are other important factors that contribute to the higher mortality rate in Iran.

Although using time series can overcome problems occurring due to seasonal and past trends, it cannot control other variables including the number of vehicles, change in socio-economic status, application of new laws about helmet and seat belt usage, and implication of educational programs. Thus, in this model, we assumed that all such factors did not change effectively over the period of the study. In addition, we could not specify the exact number of vehicles in the province, and therefore, we also assumed that no significant changes occurred in this value.

\section{Conclusion}

According to the results of this study, there is no relationship between road traffic fatalities and petroleum price and rationing. However, a further decrease in fatality rate necessitates additional focus on reinforcement of laws, application of heavy fines for offending drivers and safety standards for all produced vehicles, and educational programs for drivers. In fact, gasoline rationing was a useful measure in dealing with gasoline sanctions in Iran with no effect on the rate of fatality due to road traffic accidents. 


\section{Acknowledgement}

The present article was extracted from the thesis written by Mehdi Moradinazar and was financially supported by Shiraz University of Medical Sciences, Iran (no 6099).

Conflict of interests: None declared.

\section{Reference}

1. Wesemann P. Economic evaluation of road safety measures. Paris: SWOV Institute for Road Safety Research; 2000. 40 p. Report No.: D-2000-16E.

2. Murray CJ, Lopez AD. Alternative projections of mortality and disability by cause 1990-2020: Global Burden of Disease Study. Lancet 1997; 349(9064):1498-504.

3. Peden M, Scurfield R, Sleet D, Mohan D, Hyder AA, Jarawan E, etal. World report on road traffic injury prevention: Summary. Geneva: World Health Organization; 2004. 52 p.

4. Peden M, Scurfield R, Sleet D, Mohan D, Hyder AA, Jarawan E, et.al. World report on road traffic injury prevention (Summary). Geneva: World Health Organization; 2004.

5. Peden M. Global collaboration on road traffic injury prevention. Int $\mathrm{J}$ Inj Contr Saf Promot 2005;12(2):85-91.

6. Akbari ME, Naghavi M, Soori H. Epidemiology of deaths from injuries in the Islamic Republic of Iran. East Mediterr Health J 2006; 12(3-4):38290.

7. Murray CJ, Lopez AD. Alternative projections of mortality and disability by cause 1990-2020: Global Burden of Disease Study. Lancet 1997; 349(9064):1498-504.

8. Naghavi M, Akbari ME (2002). Epidemiology of injuries resulting from extrinsic causes (accidents) in Islamic Republic of Iran. Tehran: Fekrat Cultural Publishing Institute.

9. Soori H, Royanian M, Zali AR, Movahedinejad A. Road traffic injuries in Iran: the role of interventions implemented by traffic police. Traffic Inj Prev 2009; 10(4):375-8.

10. Soori H, Ainy E, Movahedinejad AA, Mahfozphoor S, Movahedi M, Rezazadeh Azari M, Vafaee R, Hatamabadi HR, Masoodeinejad MR. A Practical Model of Political Mapping in Road Traffic Injury in Iran in 2008. Hakim 2009;12(3):1-9.
11. Spoerri A, Egger M, von Elm E; Swiss National Cohort Stuty. Mortality from road traffic accidents in Switzerland: Longitudinal and spatial analyses. Accid Anal Prev 2011; 43(1):408.

12. Saadat S, Mafi M, Sharif-Alhoseini M. Population based estimates of non-fatal injuries in the capital of Iran. BMC Public Health 2011; 11(1):600-8.

13. Houri Jafari H, Baratimalayeri A. The crisis of gasoline consumption in the Iran's transportation sector. Energy Policy 2008; 36(7):2536-43.

14. The Office of information technology. Statistical Yearbook of Road Maintenance and Transportation Organization of the road in Iran Tehran: Department of Transportation; 2007. P 350.

15. Brämer GR. International statistical classification of diseases and related health problems. Tenth revision. World Health Stat Q 1988; 41(1):32-6.

16. Box GEP, Jenkins GM, Reinsel GC (2008). Time series analysis: forecasting and control. $4^{\text {th }}$ ed. Hoboken, New Jersey: John Wiley \& Sons. P 1218.

17. Brockwell PJ, Davis RA. Time series: theory and methods. 2 $2^{\text {nd }}$ Edition. New York: SpringerVerlag; 2009.

18. Bahadorimonfared A, Soori H, Mehrabi Y, Delpisheh A, Esmaili A, Salehi M, et al. Trends of fatal road traffic injuries in Iran (2004-2011). PloS One 2013; 8(5):e65198.

19. Crandon IW, Harding HE, Cawich SO, McDonald AH, Fearron-Boothe D. Motorcycle accident injury profiles in Jamaica: An audit from the University Hospital of the West Indies. Int J Inj Contr Saf Promot 2009;16(3):175-8.

20. Mayhew DR, Ferguson SA, Desmond KJ, Simpson HM. Trends in fatal crashes involving female drivers, 1975-1998. Accid Anal Prev 2003; 35(3):407-15.

21. Bedard M, Guyatt GH, Stones MJ, Hirdes JP. The independent contribution of driver, crash, and vehicle characteristics to driver fatalities. Accid Anal Prev 2002; 34(6):717-27.

22. Blaizot S, Papon F, Haddak MM, Amoros E. Injury incidence rates of cyclists compared to pedestrians, car occupants and powered twowheeler riders, using a medical registry and mobility data, Rhône County, France. Accid Anal Prev 2013; 58:35-45.

23. Novoa AM, Pérez K, Santamariña-Rubio E, Marí-Dell'Olmo M, Ferrando J, Peiró R, et al. Impact of the penalty points system on road 
traffic injuries in Spain: a time-series study. Am J Public Health 2010; 100(11):2220-7.

24. Pitaktong U, Manopaiboon C, Kilmarx PH, Jeeyapant S, Jenkins R, Tappero J, et al. Motorcycle helmet use and related risk behaviors among adolescents and young adults in Northern Thailand. Southeast Asian J Trop Med Public
Health 2004; 35(1):232-41.

25. Mercer GW, Jeffery WK. Alcohol, drugs, and impairment in fatal traffic accidents in British Columbia. Accid Anal Prev 1995; 27(3):335-43.

26. Asayesh H, Halim AA Jawan JA, Shojaei SN. Political Party in Islamic Republic of Iran: A Review. J Politics Law 2011; 4(1):221-30. 